\title{
Australian Fine Art as an Alternative Investment
}

\author{
Andrew C. Worthington and Helen Higgs \\ Department of Accounting, Finance and Economics \\ Griffith University
}

\begin{abstract}
Purpose- This paper examines the investment characteristics of works by leading Australian artists.

Design/methodology/approach - 35,805 paintings by 45 leading Australian artists sold at auction are used to construct individual hedonic price indices. The attributes included in each artist's hedonic regression model include the size and medium of the painting and the auction house and year sold.

Findings - The indexes show that average annual returns across all artists range between 4 and 15 percent with a mean of 8 percent, with the highest returns for works by Brett Whiteley, Jeffrey Smart, Cecil Brack and Margaret Olley. Risk-adjusted returns are generally lower, with reward-to-volatility and reward-to-variability ratios averaging 1.5 percent and 5.8 percent, respectively. The portfolio betas for individual artistic works average 0.41 . The willingness-to-pay for perceived attributes in the artwork show that works executed in oils and gouache, and those auctioned by Deutscher-Menzies, Sotheby's and Christies are generally associated with higher prices.
\end{abstract}

Research implications - The returns on a buy-and-hold strategy in the Australian art market are at least comparable to the Australian stock market. While total risk is greater, the very low market risk found in almost all artistic portfolios is suggestive of the possible benefits of portfolio diversification through art investment. Moreover, a number of artist's works offer very superior market and non-market risk-adjusted performance.

Originality/value - This is the first Australian study to construct measures of risk, return, beta and Sharpe and Treynor ratios for individual Australian artists.

Keywords Hedonic price index, art investment, risk-adjusted returns

Paper type Research paper

\section{Introduction}

For some time, investors have been turning to art (paintings, sculpture, ceramics and prints, and collectibles such as coins, stamps, antiques and furniture) as an alternative investment. In Australia too, there is burgeoning interest in art investment, particularly the work of Australian artists. Of course, Australia has a long history of world-renowned artists, including Frederick McCubbin, Arthur Streeton, Tom Roberts and Arthur Boyd, to name just a few. But in the last few decades many modern and contemporary painters, like Charles Blackman, Brett Whiteley, David Boyd, Ray Crooke and John Olsen, have also produced internationally reputable works and thereby raised public awareness of art as a potential investment opportunity.

The purpose of this paper is to inform this process by investigating the risk, return and asset pricing of Australian art. Hedonic pricing equations are used to capture the characteristics of artwork by 45 well-known Australian artists publicly auctioned during the past thirty years. The paper itself is organised as follows. Section 2 outlines the empirical methodology. Section 3 provides a description of the data employed. The empirical results are dealt with in Section 4. The paper ends with some concluding remarks in Section 5. 


\section{Empirical Methodology}

The method selected to examine the investment characteristics of Australian art is the hedonic price method [see, for instance, Buelens and Ginsburgh (1993), de la Barre et al. (1994), Chanel (1995) and Agnello and Pierce (1996)]. In this approach, all sales (including repeat sales) are considered as single sales for which the objective features are recorded (i.e. name of the painter, size of painting, medium of execution, etc.). Combining all sales allows the implicit (or shadow) prices for these characteristics to be estimated separately from a characteristic-free price including only the effects of time and random error. Assuming the availability of comprehensive data, the hedonic price method's main strengths are that it estimates values based on actual auction sales and captures the willingness-to-pay for perceived differences in the attributes of the artwork. The hedonic price equation is written as:

$\ln p_{k t}=f\left(X_{1 k t}, \ldots, X_{m k t}, \ldots, X_{M k t}\right)+g(t)+{ }_{k t}$

where $\ln p_{k t}$ is the natural logarithm of the price of painting $k(k=1, \ldots, K)$ sold in year $t$ $(t=1, \ldots, T), X_{m k t}$ is the measurable characteristics $m(m=1, \ldots, M)$ of painting $k$ at time $t, g(t)$ is a function of time, and the error term $\varepsilon \sim N\left(0, \Sigma_{k} \otimes I_{T}\right)$. The measurable characteristics of the paintings for each artist comprise the physical characteristics of the work and the characteristics of the auction at which the sale took place. The regression equation is then specified as:

$$
\ln p_{k t}=\sum_{m=1}^{M} \alpha_{m} X_{m k t}+\sum_{t=1}^{T} \beta_{t} Z_{t}+\varepsilon_{k t}
$$

where $\alpha_{m}$ are parameter estimates of the implicit prices of the specified art characteristics, $Z_{t}$ is a dummy variable which takes the value of one for a sale occurring in year $t$ and zero elsewhere, $\beta_{t}$ is a parameter estimate, $e^{\beta t}$ gives the characteristic-free price and all other variables are as previously defined. Separate regression equations are specified for each artist.

The data used comprises 35,805 sales of artworks by 45 leading Australian artists. Information on sales is obtained from Australian Art Auction Records (2003) and spans a 30 year period since March 1973. While an update of this data has just become available, the requirement for extensive and lengthy data entry and manipulation acted against this in the current analysis. The selection of artists to be included in the analysis is, of course, highly subjective and was arrived at after discussion with various art auctioneers, curators and dealers on those artists whose works were most sought after and frequently sold at auction in the past thirty years. Its construction is also reflective, in so far is possible, of the widest number of periods, schools and genres in Australian art history and is purposively restricted to artists who lived most of their lifetime in Australia. A list of the artists is provided in Table 1 (column 1).

The first set of information gathered is the price of each artwork for each artist. This comprises the dependent variable in the hedonic price regression. Each artwork included is sold exclusively at public auction and its value specified in Australian dollars.

The next two sets of variables are considered to be major determinants of the price of an artist's work and are specified as explanatory variables. The first set of explanatory variables relate to the physical characteristics of the work, while the second set comprise its sale characteristics. Starting with the physical characteristics of the works, the first group comprises dummy variables identifying the medium used: namely, acrylic, charcoal, crayon, etching, the heavy, opaque watercolour paint known as gouache, mixed media, oil, pastel, 
pencil and watercolour. The reference category is all other mediums. Of the mediums used by artists in the sample, the largest numbers of works (percentage of all mediums in brackets) sold are oils (44\%), followed by watercolours (11\%), and finally etchings (8\%). Oil as a medium, though difficult to work, has excellent visual qualities and is not easily faded by natural light. It is therefore likely to fetch higher prices at auction. Modern alternatives, including acrylic and gouache, also command high prices. However, a variety of other potentially valuable media are found in most fine art collections. Australian landscape artists, for instance, often favour watercolours.

The second group of physical characteristic are the dimensions of the painted work as represented by surface area in square metres $\left(\mathrm{m}^{2}\right)$ and surface area squared as the nonlinear component. A positive relationship is generally hypothesised when price is regressed against area, although it is difficult for all but the largest public galleries to display very large works. On this basis, the expected sign on the coefficient for area squared is thought to be negative (Agnello and Pierce, 1996). Of course, there are any number of other physical characteristics that could be included if data were available. These include the painting's genre, providence, date completed, the presence of the artist's signature and so on.

The second set of explanatory variables incorporate the sales characteristics of the work. The first of these are dummy variables identifying in which of Australia's three largest auction houses the sale took place (percentage of all sales in brackets): that is, Christies (16\%), Deutscher-Menzies (4\%) and Sotheby's (15\%). The reference category is all other auction houses. In the absence of transaction costs, the law of one price dictates that no significant price difference should exist for paintings of a similar quality. However, Pesando (1993), de la Barre et al. (1994) and Renneboog and Van Houtte (2002), amongst others, have found that Christies and Sotheby's systematically obtain higher hammer prices through their reputation and market power. The second group of sales characteristics identifies the year when the work is sold. This consists of thirty yearly dummy variables with 1973 as the reference category.

\section{Descriptive Analysis}

The mean and standard deviation of prices for each artist's works are included in Table 1 (columns 2 and 3). Turning first to the prices of artworks by artist, average prices range from $\$ 796$ for paintings by Boyd (Jamie) to \$55,245 for works by McCubbin. Other artist's with highly valued works are Russell, Smart and Brack with means of \$45,167, \$36,544 and $\$ 35,010$, respectively. The lowest prices are paid for works by Hart, Hodgkinson and Fizelle with average prices of $\$ 1,442, \$ 1,526$ and $\$ 1,564$, respectively. The standard deviations of art prices by artist range from $\$ 872$ to $\$ 171,014$. On this basis, works by Boyd (Jamie), Hodgkinson, Hart and Boyd (David) are the least volatile with standard deviations of \$872, \$2,509, \$2,674 and \$2,772, respectively, whereas works by McCubbin, Drysdale, Russell and Whiteley are the most volatile with standard deviations of $\$ 171,014, \$ 115,731, \$ 100,079$ and $\$ 82,465$, respectively.

\section{$<$ TABLE 1 HERE >}

Now consider each artist's work categorised according to the media used (not shown). Of these, oils, watercolours and etchings are the most common medium sold, while crayons and acrylics are the least common. However, the distribution of all physical and sales characteristics varies dramatically by artist. For example, sold work by Nolan, Fullbrook and Bunny are almost exclusively oil, while Namatjira's sold works are primarily watercolours. Similarly, the distribution of sold works by auction house also varies across the artists. For 
example, 54 percent of Whiteley's work was sold at Christies, 32 percent of Brack's at Deutscher-Menzies and 54 percent of Fullbrook's at Sotheby's. This contrasts markedly to the aforementioned sample averages.

\section{Empirical Results}

In the interests of brevity, the estimated coefficients of the hedonic pricing regression models for each of the 45 Australian artists are not shown. All of the estimated models are highly significant, with likelihood ratio tests (not shown) of the hypotheses that the slope coefficients are zero rejected at the 1 percent level. The adjusted $\mathrm{R}^{2}$ range between 0.547 and 0.889 and are reasonably high for what is basically cross-sectional data.

As hypothesised, the percentage changes in value indicate that works executed in oil and gouache command higher prices, with average percentage increases over each artist's standard work of 6.799 and 6.733 percent, respectively. Of the 44 artists in the sample with at least some oil works, all but one have significant and positive increases in value relative to other work, while 28 of the 30 artists with gouache works have significant and positive increases with this media. However, the percentage increases in value for individual artists vary widely. For example, with oils the increase in values ranges from as little as 1.188 percent (Fizelle) to more than 21.700 percent (Bracks) and for gouache from just 0.684 percent (Olley) to 68.217 percent (Smith).

By comparison, media such as etchings, crayon and charcoal are associated with respective average percentage increases across the sample of just $1.105,3.020$ and 1.787 percent implying these media are generally more affordable, regardless of all other characteristics, while mixed media, watercolours and pastels have average price increases across the sample of 3.466, 3.346 and 3.646 percent, respectively. Unfortunately, it is difficult to compare these findings because other studies are often limited to periods or movements when fewer media are generally known (de la Barre et al., 1994; Renneboog and Van Houtte, 2002) or to a single medium (Candela and Scorcu, 1997; Pesando and Shum, 1999). Nevertheless, Agnello and Pierce (1996) found a 156 percent increase in prices for oil works as compared to all other media (watercolour, gouache, ink, pencil, pastel, etc.).

The remaining physical characteristics included in the regression models concern the size of the work. These are the area of the work in square metres and its nonlinear component, area squared. The generally positive and significant signs of the area coefficients and the negative and significant signs of its squared term indicate that art prices tend first to increase with size, then decrease as the paintings become too large and difficult to house. Across the sample, a one percent increase in surface area is associated with a 0.206 percent increase in price, while on average the price-maximising size is 4.08 square metres. By comparison, Agnello and Pierce (1996) found the price-maximising size for American artists' work to be 6.53 square metres while de la Barre et al. (1994) calculated this optimal size to be 5.89 square metres for Old Masters and 1.70 square metres for Modern and Contemporary European works.

The final set of variables relates to the sale characteristics of the works. The sales characteristics show that auctions at Sotheby's, Christies and Deutscher-Menzies increase the average standard price by $1.759,1.697$ and 1.869 percent, respectively, over the remaining houses. Pesando (1993), de la Barre et al. (1994), Agnello and Pierce (1996) and Renneboog and Van Houtte (2002) also found that “...Sotherby's typically fetches higher prices than Christies, while both experience higher prices than all other houses” (Agnello and Pierce 1996: 366). However, while variation in the prices obtained by the different auction houses are small, and certainly smaller than most other factors included in the model, care should still be taken in interpreting these differences as a violation of the law of one price. De la Barre et 
al (1994: 165), for example, concluded “...the quality of a painting, not captured by our characteristics is partly picked up by the saleroom coefficients: a 'good' Picasso would go to Christies or Sotheby's New York, a less good one would be sold at Drouot's [a Paris-based auction house]... it is impossible to disentangle the two effects".

Turning to investment risk and return, the index value for each artist is calculated as $100 \mathrm{e}^{\beta t}$ (not shown). Annual returns are then calculated such that the return for artist $i$ is represented by the continuously compounded return or log return of the price index at time $t$ such that $\Delta p_{i t}=\log \left(p_{i t} / p_{i t-1}\right) \times 100$ where $\Delta p_{i t}$ denotes the rate of change of $p_{i t}$. Table 1 presents the arithmetic mean and standard deviation (risk) of annual returns and their ranks for the 45 Australian artists (columns 4 to 7).

Also included in Table 1 are two external risk-adjusted portfolio performance measures. The Sharpe ratio and its rank (also known as the reward-to-volatility ratio) (columns 8 and 9) indicates the excess return per unit of risk and is calculated by dividing the return in excess of the risk-free rate by the standard deviation of returns. The proxy used for the risk-free rate is the exponentially smoothed average fitted yield for 3-year Commonwealth Treasury bonds during the sample period (5 percent). In the current context, the Sharpe ratio is the most appropriate performance measure for an investor whose portfolio is composed wholly of a given artist's work.

The Treynor ratio and its rank (sometimes called the reward-to-variability ratio) (columns 10 and 11) is identical to the Sharpe ratio except that total risk (standard deviation) is replaced with systematic (market) risk or beta. This ratio may be a better benchmark of performance for investors who do not invest exclusively in art, but rather consider its diversification potential. Accordingly, the beta of each artist's portfolio and its rank (columns 12 and 13) is calculated with respect to an equity market portfolio. The Australian All Ordinaries index (AOI) is specified as the equity market measure. Since higher Sharpe and Treynor ratios represent better performance, the artistic portfolios are ranked in descending order.

In terms of returns, mean returns for the individual artists range between 3.70 percent for works by Friend to 14.70 percent for those by Whitelely. Annual returns across all artists average 8.23 percent, as compared to mean returns on the AOI of 7.00 percent over this same period. Other artists with relatively high returns include Smart, Brack, Olley, Smith, Proctor and Olsen, with relatively low returns for Withers, Gruner, Dargie, Crooke, Nolan, Lindsay and Boyd (Arthur). The standard deviation (risk) of returns ranges between 0.189 (Hart) to 1.933 (Roberts) with a mean of 0.449. By way of comparison, the standard deviation of returns on the AOI over this same period was 0.161 . Risk is also relatively higher for works by Russell, Heysen (Nora), Fullbrook and Fairweather and relatively lower for works by Dickerson, Lindsay, Boyd (David) and Crooke.

For overall returns on Australian art, it would appear that the market has performed at a comparable level to other national markets. Renneboog and van Houtte (2002), for example, found Belgian average returns of 8.4 percent over the period 1970-1989 with a standard deviation of 19.4 percent, Agnello and Pierce (1996) estimated that the returns on American artists averaged 9.3 percent from 1971-1992, and Mei and Moses (2001) calculated average returns of 5.3 percent with a standard deviation of 9.3 percent, also on American auctions. Mean returns from other art studies include 1.6 percent (Frey and Pommerehne, 1989), 6.8 percent (Gerard-Varet, 1995) and 5.0 percent (Goetzmann, 1996). Using a different methodology and an international sample, Worthington and Higgs $(2003,2004)$ found mean returns of 3.73 percent for Contemporary Masters, 2.85 percent for $20^{\text {th }}$ Century English works, 1.49 percent for Modern Europeans and 1.25 percent Surrealists. Of course, the returns as calculated in this paper do not reflect the fact that a substantial component of the return 
from art investment is derived not from its financial returns, rather from its intrinsic aesthetic qualities. Equally, they also do not include the many and sizeable transaction and holding costs associated with art portfolios, the absence of which may serve to inflate the financial returns.

Analysis of the risk-adjusted returns for each artist's portfolio of works provides further insights. Starting with the Sharpe ratio, artists ranked highly on the basis of returns per unit of (total) risk include Whiteley (0.345), Smart (0.211), Olley (0.210), Brack (0.155) and Proctor (0.172). The Sharpe index for the AOI over this same period is 0.124 while that for the average artist included in the sample is just 0.015. As shown, many artists have low Sharpe ratios (and rankings) suggesting that a policy of holding high-return-high-risk portfolios of a single artist's work in isolation may not be an appropriate investment strategy. As an alternative, the Treynor ratio show the returns per unit of (systematic) risk and thus yields useful insights on the benefit of holding Australian art as part of a diversified portfolio (though, of course, limited in this analysis to listed equity).

As shown in Table 1, the betas of most Australian artist's work are low (less than one), if not negative, indicating potential diversification benefits. For example, the negative betas calculated on art portfolios composed of works by Hodgkinson, Proctor, Gruner, Coburn and Williams indicate that their returns move contrary to returns on the Australian stock market. However, some art portfolios are substantially more risky (in terms of beta) than the market, and move in the same direction, including Russell, Smith, Boyd (Jamie), Preston and Fox. The average beta across the sample is 0.405 with 25 percent of artistic portfolios having a beta less than 0.075 and 25 percent greater than 0.566. By comparison, Chanel et al. (1994) calculated that national art betas ranged between 0.028 (London) and 0.368 (Tokyo), while Renneboog and van Houtte (2002) estimated movement betas with respect to a global stock index of $-3.7,-2.9$ and 0.8 for Impressionist, Luminist and Expressionist art, respectively.

The Treynor ratios for the 45 artist portfolios in mean/beta-space are graphically represented in Figure 1. The figure includes the security market line constructed using the risk-free rate (intercept) and the return and beta (one) for the market portfolio (slope). Visual inspection indicates that few artist portfolios are correctly priced in relation to the security market line (that is, on the line) with most underpriced. That is, artist portfolios lying above the line indicate superior market risk-adjusted returns and a buy signal, while those lying below the line indicate inferior market risk-adjusted returns and a sell signal. Artists ranked highly on the basis of the Treynor index include Streeton, McCubbin, Whiteley, Long and Brack. A buy signal is indicated for these artists. Those ranked lowly with a consequent sell signal include Smart, Olsen, Fullbrook, Fairweather and Glover.

\section{$<$ FIGURE 1 HERE $>$}

Of course, these buy-and-sell strategies must be qualified by the fact that they relate to historical information averaged over a thirty year investment horizon, not the immediate past, present or future. It should also be remembered that the Treynor ratio reflects only systematic (general or market) risk and thereby reflects the value of these assets within a diversified portfolio. The change in rankings of artists between the Sharpe and Treynor measures indicate that most art portfolios as analysed include much unsystematic (asset specific or nonmarket) risk when held in isolation. Nonetheless, while the rankings of artists on the Sharpe and Treynor criterion do vary, there is some deal of correspondence between them with the Spearman (rank) correlation coefficient signifying a significant and positive relationship ( $\rho=$ $0.319, p$-value $=0.033)$.

$<$ FIGURE 2 HERE $>$ 
A final requirement is to examine the relationship between the returns and values of works included in each artistic portfolio. This follows the suggestion of Mei and Moses (2001) amongst others that bidders in art auctions are exposed to a 'winner's curse' so that the returns on expensive paintings tend to under perform the market as a whole: referred to as the 'masterpiece effect'. Figure 2 plots the returns and mean prices of paintings for each artist, with a linear trendline added as a simple means of evaluating the relationship between value and return. As shown, there is a small positive $(1.03 \mathrm{E}-06)$ and significant ( $p$-value $=0.019$ ) relationship suggesting that returns increase with value, thereby supporting the absence of a 'masterpiece effect' effect.

\section{Conclusion}

This paper investigates risk, return and asset pricing for the works of 45 well-known Australian artists. Unlike most other work in this area which indicates that the returns to art investment are much less, and the risks much higher than investment markets, the results show that return on a buy-and-hold strategy in the Australian art market are at least comparable to the stock market. While total risk is indeed greater than the stock market, the very low market risk found in almost all artistic portfolios is highly suggestive of the possible benefits of portfolio diversification through art investment.

That said, a number of artist's works offer superior market and non-market risk-adjusted performance over the sample period, above all Arthur Streeton, Frederick McCubbin, Brett Whiteley, Sydney Long, Cecil Brack, Frank Smart, Margaret Olley and Althea Proctor. One major qualification is that the analysis does not take into account the (high) transaction costs incurred at the moment of sale nor the (equally sizeable) insurance and other costs associated with restoring, preserving and displaying art works. However, neither does it take into account the (equally substantial) aesthetic returns from owning and displaying fine art. The methodology employed in the paper also identifies factors associated with higher prices in the Australian art market. All other things being equal, larger-sized works and those executed in oils or gouache, and auctioned by Sotheby's or Christies are associated with higher prices. Conversely, smaller works, etchings, crayon or charcoal works, along with those auctioned by other auction houses, are associated with systematically lower prices.

There are many interesting opportunities to expand upon this work. One possibility would involve gathering additional information to be included in the hedonic pricing regression models. For example, the prices (and hence returns) on artists' work may also depend on the cumulative number of works auctioned, whether the artist is now deceased or the age of the artist at the time of auction, genres of work, interactions between medium and size and so on. While these impacts are proxied to some extent by the variables included in the current analysis, a more defined specification would identify some determinants potentially obscured. There may also be opportunities to examine art markets along the lines of the market efficiency literature. One prospect is to examine the time-series behaviour of returns to examine whether the art market fully incorporates all historical market information (weakform efficient).

Finally, the art works on which these indices are based may not reflect the market for Australian paintings as a whole: private transactions for example conducted through art galleries are ignored. Depending on the values found in galleries, indexes constructed using auction data may understate or overstate the true return. There is also no recognition that different buyers in the market have differing preferences for art work: compare, for instance, works bought by public galleries to those purchased privately. For this reason, sellers of art to 
public collections are argued to enjoy systematically higher rates of return. Future work could take into account these subtleties.

\section{References}

Agnello, R.J., and R.K. Pierce, 1996, Financial returns, price determinants, and genre effects in American art Investment, Journal of Cultural Economics 20, 359-383.

Australian Art Auction Records Pty. Ltd., 2003, Australian Art Auction Records, 1972-2003, CD, Sydney.

Buelens, N., and V. Ginsburgh, 1993, Revisiting Baumol’s 'art as a floating crap game', European Economic Review 37, 1351-1371.

Candela, G., and A.E. Scorcu, 1997, A price index for art market auctions, Journal of Cultural Economics 21, 175-196.

Chanel, O., 1995, Is art market behaviour predictable?, European Economic Review 39, 519-527.

Chanel, O., L.A. Gerard-Varet, and V. Ginsburgh, 1994, Prices and returns on paintings: An exercise on how to price the priceless, Geneva Papers on Risk and Insurance Theory 19, 7-21.

de la Barre. M., S. Docclo, and V. Ginsburgh, 1994, Returns of Impressionist, Modern and Contemporary European paintings 1962-1991, Annales d'Economie et de Statistique 35, 143-181.

Frey, B., and W. Pommerehne, 1989, Art investment: An empirical inquiry, Southern Economic Journal 56, 396-407.

Gerard-Varet, L.A., 1995, On pricing the priceless: Comments on the economics of the visual art market, European Economic Review 39, 509-518.

Goetzmann, W.N., 1993, Accounting for taste: Art and the finance markets over three centuries, American Economic Review 83, 1370-1376.

Goetzmann, W.N., 1996, How costly is the fall from fashion? Survivorship bias in the painting market, in V.A. Ginsburgh and P.M. Menger, eds., Economics of the Arts: Selected Essays (Elsevier North-Holland, Amsterdam) 7184.

Mei, J., and M. Moses, 2001, Art as an investment and the origin of the masterpiece effect: Evidence from 1875-2000, paper presented at the $8^{\text {th }}$ Asia-Pacific Finance Association Annual Conference, Shangri-La Hotel, Bangkok, Thailand, 22-25 July.

Pesando, J.E., 1993, Arts as an investment: The market for modern prints, American Economic Review 83, $1075-1089$.

Pesando, J.E., and P.M. Shum, 1999, The returns to Picasso’s prints and to traditional financial assets, 1977 to 1996 , Journal of Cultural Economics 23, 183-192.

Renneboog, L., and T. van Houtte, 2002, The monetary appreciation of paintings: From Realism to Magritte, Cambridge Journal of Economics 26, 331-357.

Worthington, A.C., and H. Higgs, 2003, Art as an investment: Short and long-term comovements in major painting markets, Empirical Economics 28, 649-668.

Worthington, A.C., and H. Higgs, 2004, Art as an investment: Risk, return and portfolio diversification in major painting markets, Accounting and Finance 44, 257-272. 
Table 1

Prices, return and risk, performance measures and betas by artist

\begin{tabular}{|c|c|c|c|c|c|c|c|c|c|c|c|c|}
\hline \multirow[t]{2}{*}{ Artist } & \multicolumn{2}{|c|}{ Prices } & \multicolumn{2}{|c|}{ Return } & \multicolumn{2}{|c|}{ Risk } & \multicolumn{2}{|c|}{$\begin{array}{l}\text { Sharpe } \\
\text { ratio }\end{array}$} & \multicolumn{2}{|c|}{$\begin{array}{c}\text { Treynor } \\
\text { ratio }\end{array}$} & \multicolumn{2}{|c|}{ Beta } \\
\hline & Mean & Std. dev. & Statistic & Rank & Statistic & Rank & Statistic & Rank & Statistic & Rank & Statistic & Rank \\
\hline Ashton, John & $\$ 2,649$ & $\$ 3,782$ & 0.062 & 33 & 0.264 & 7 & 0.045 & 25 & 0.044 & 18 & 0.271 & 28 \\
\hline Blackman, Charles & $\$ 8,006$ & $\$ 20,495$ & 0.077 & 23 & 0.277 & 10 & 0.097 & 22 & 0.075 & 10 & 0.358 & 23 \\
\hline Boyd, Arthur & $\$ 20,426$ & $\$ 57,305$ & 0.057 & 38 & 0.317 & 17 & 0.022 & 35 & 0.030 & 22 & 0.232 & 30 \\
\hline Boyd, David & $\$ 2,693$ & $\$ 2,772$ & 0.063 & 30 & 0.211 & 4 & 0.062 & 36 & 0.035 & 20 & 0.373 & 21 \\
\hline Boyd, Jamie & $\$ 796$ & $\$ 872$ & 0.066 & 28 & 0.612 & 40 & 0.026 & 27 & 0.014 & 28 & 1.153 & 3 \\
\hline Brack, Cecil John & $\$ 35,010$ & $\$ 76,521$ & 0.138 & 3 & 0.566 & 38 & 0.155 & 4 & 0.273 & 5 & 0.322 & 26 \\
\hline Bunny, Rupert & $\$ 23,837$ & $\$ 75,640$ & 0.082 & 21 & 0.447 & 32 & 0.072 & 20 & 0.036 & 19 & 0.897 & 7 \\
\hline Coburn, John & $\$ 3,497$ & $\$ 6,386$ & 0.083 & 19 & 0.297 & 15 & 0.111 & 18 & -0.113 & 38 & -0.291 & 42 \\
\hline Crooke, Ray & $\$ 4,000$ & $\$ 6,472$ & 0.051 & 41 & 0.232 & 5 & 0.004 & 44 & 0.003 & 33 & 0.343 & 24 \\
\hline Dargie, William & $\$ 1,931$ & $\$ 4,317$ & 0.049 & 42 & 0.533 & 37 & -0.002 & 34 & -0.001 & 34 & 0.970 & 6 \\
\hline Dickerson, Robert & $\$ 4,326$ & $\$ 8,121$ & 0.092 & 16 & 0.200 & 2 & 0.210 & 10 & 0.116 & 7 & 0.362 & 22 \\
\hline Drysdale, George Russell & $\$ 32,940$ & $\$ 115,731$ & 0.059 & 34 & 0.401 & 26 & 0.022 & 32 & 0.022 & 25 & 0.418 & 19 \\
\hline Fairweather, Ian & $\$ 19,699$ & $\$ 29,316$ & 0.101 & 14 & 0.659 & 41 & 0.077 & 16 & -0.333 & 42 & -0.153 & 38 \\
\hline Fizelle, Reginald Cecil & $\$ 1,564$ & $\$ 4,762$ & 0.067 & 27 & 0.447 & 32 & 0.038 & 28 & 0.033 & 21 & 0.522 & 17 \\
\hline Fox, Ethel & $\$ 10,172$ & $\$ 20,197$ & 0.074 & 24 & 0.484 & 36 & 0.050 & 25 & 0.024 & 23 & 1.017 & 5 \\
\hline Friend, Donald & $\$ 4,272$ & $\$ 8,501$ & 0.037 & 45 & 0.348 & 19 & -0.037 & 45 & -0.023 & 36 & 0.5 & 13 \\
\hline Fullbrook, Samuel & $\$ 8,042$ & $\$ 10,575$ & 0.10 & 14 & 0.775 & 42 & 0.066 & 17 & -0.392 & 44 & -0.130 & 37 \\
\hline Gleeson, James Timothy & $\$ 3,310$ & $\$ 7,225$ & 0.07 & 24 & 0.294 & 14 & 0.082 & 24 & 0.099 & 8 & & 29 \\
\hline Glover, John & $\$ 10,572$ & $\$ 48,580$ & & 29 & & 35 & 0.030 & 29 & -0.326 & 41 & -0.043 & 36 \\
\hline Gruner, Elioth & $\$ 11,195$ & $\$ 14,824$ & 0.048 & 43 & 0.423 & 28 & -0.005 & 39 & 0.007 & 32 & -0.304 & 43 \\
\hline Hart, Kevin Charles (Pro) & $\$ 1,442$ & $\$ 2,674$ & 0.058 & 37 & 0.189 & 1 & 0.042 & 42 & 0.070 & 14 & 0.114 & 33 \\
\hline inson, $\mathrm{Fr}$ & 1,526 & $\$ 2,509$ & 107 & 8 & 0.600 & 39 & 0.095 & 14 & -0.098 & 37 & -0.582 & 45 \\
\hline , Hans & $\$ 8,571$ & $\$ 16,653$ & .059 & 34 & 0.235 & 6 & 0.038 & 40 & 0.014 & 29 & 0.662 & 9 \\
\hline , Nora & $\$ 3,158$ & $\$ 5,383$ & 0.074 & 24 & 0.847 & 43 & 0.028 & 26 & 0.072 & 12 & 0.334 & 25 \\
\hline James Ranalph & $\$ 5,894$ & $\$ 9,662$ & 0.059 & 34 & 0.274 & 9 & 0.033 & 37 & 0.016 & 27 & 0.568 & 11 \\
\hline , Norman & $\$ 5,822$ & $\$ 13,657$ & 0.057 & 38 & 0.201 & 3 & 0.035 & 43 & 0.012 & 30 & 0.606 & 10 \\
\hline Long, Sydney & $\$ 4,073$ & $\$ 8,702$ & 0.092 & 16 & 0.301 & 16 & 0.140 & 13 & 0.328 & 4 & 0.128 & 32 \\
\hline McCubbin, Frederick & $\$ 55,245$ & $\$ 171,014$ & 0.103 & 10 & 0.434 & 30 & 0.122 & 11 & 0.697 & 2 & 0.076 & 34 \\
\hline Namatjira, Albert & $\$ 7,339$ & $\$ 6,132$ & 0.085 & 18 & 0.271 & 8 & 0.129 & 15 & 0.071 & 13 & 0.494 & 18 \\
\hline Nolan, Sidney & $\$ 11,182$ & $\$ 42,852$ & 0.054 & 40 & 0.330 & 18 & 0.012 & 38 & 0.007 & 31 & 0.562 & 14 \\
\hline Olley, Margaret & $\$ 12,529$ & $\$ 15,930$ & 0.135 & 4 & 0.404 & 27 & 0.210 & 3 & 0.159 & 6 & 0.533 & 15 \\
\hline Olsen, John & $\$ 9,118$ & $\$ 24,821$ & 0.109 & 7 & 0.391 & 22 & 0.151 & 9 & -0.383 & 43 & -0.154 & 39 \\
\hline Perceval, John & $\$ 14,133$ & $\$ 38,256$ & 0.063 & 30 & 0.398 & 24 & 0.033 & 31 & 0.073 & 11 & 0.177 & 31 \\
\hline Preston, Margaret & $\$ 12,470$ & $\$ 26,244$ & 0.102 & 12 & 0.444 & 31 & 0.117 & 12 & 0.050 & 16 & 1.047 & 4 \\
\hline Proctor, Althea & $\$ 1,867$ & $\$ 3,072$ & 0.112 & 6 & 0.361 & 21 & 0.172 & 5 & -0.138 & 39 & -0.450 & 44 \\
\hline Rees, Lloyd & $\$ 9,617$ & $\$ 20,669$ & 0.079 & 22 & 0.360 & 20 & 0.081 & 21 & 0.054 & 15 & 0.533 & 15 \\
\hline Roberts, Thomas William & $\$ 24,168$ & $\$ 48,848$ & 0.083 & 19 & 1.933 & 45 & 0.017 & 23 & 0.080 & 9 & 0.412 & 20 \\
\hline Russell, John Peter & $\$ 45,167$ & $\$ 100,079$ & 0.107 & 8 & 1.477 & 44 & 0.039 & 19 & 0.017 & 26 & 3.339 & 1 \\
\hline Smart, Frank Jeffrey & $\$ 36,544$ & $\$ 51,774$ & 0.146 & 2 & 0.456 & 34 & 0.211 & 2 & -0.593 & 45 & -0.162 & 40 \\
\hline Grace Cossington & $\$ 17,204$ & $\$ 30,323$ & 0.116 & 5 & 0.428 & 29 & 0.154 & 7 & 0.046 & 17 & 1.425 & 2 \\
\hline Streeton, Arthur & $\$ 31,800$ & $\$ 61,587$ & 0.103 & 10 & 0.283 & 12 & 0.187 & 6 & 2.304 & 1 & 0.023 & 35 \\
\hline Tucker, Albert & $\$ 14,764$ & $\$ 38,791$ & 0.063 & 30 & 0.398 & 24 & 0.033 & 30 & 0.023 & 24 & 0.566 & 12 \\
\hline Whiteley, Brett & $\$ 23,927$ & $\$ 82,465$ & 0.147 & 1 & 0.281 & 11 & 0.345 & 1 & 0.339 & 3 & 0.286 & 27 \\
\hline Williams, Frederick & $\$ 21,305$ & $\$ 49,779$ & 0.102 & 12 & 0.290 & 13 & 0.179 & 8 & -0.243 & 40 & -0.214 & 41 \\
\hline Withers, Walter & $\$ 12,097$ & $\$ 30,502$ & 0.043 & 44 & 0.392 & 23 & -0.018 & 41 & -0.009 & 35 & 0.807 & 8 \\
\hline
\end{tabular}


Figure 1

Market risk and return by artist

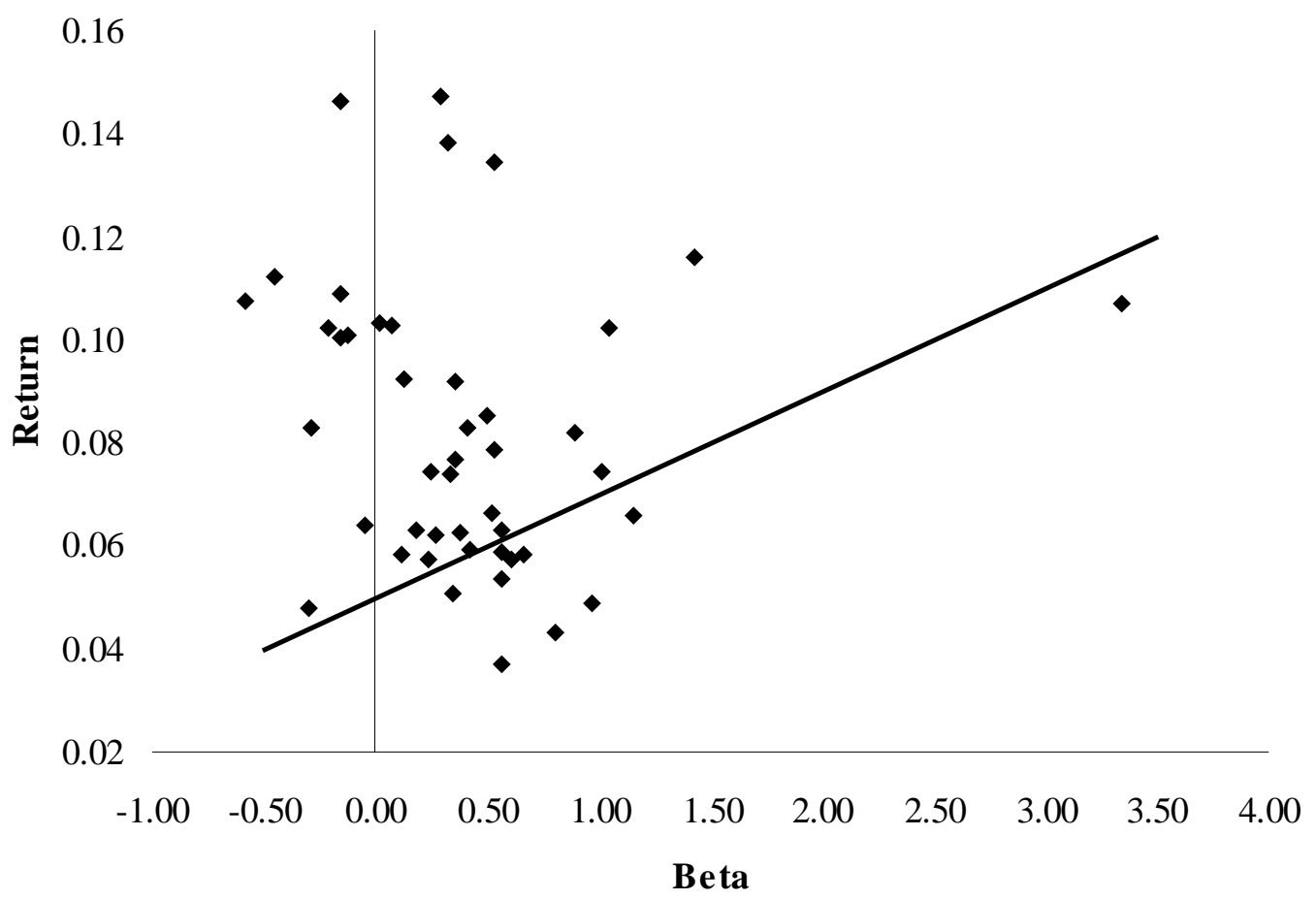

Figure 2

Mean price and return by artist

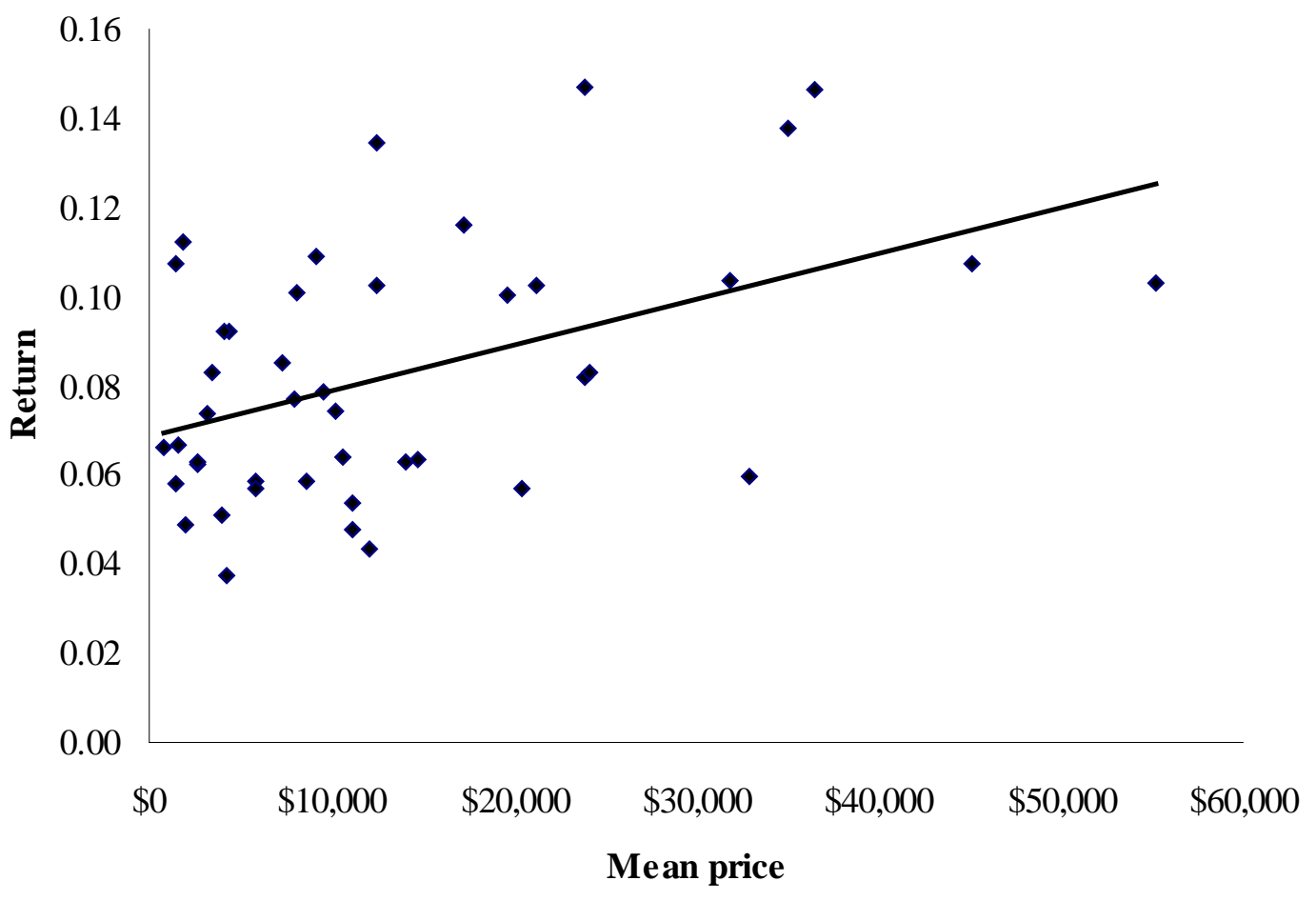

